Accelerator Department

BROOKHAVEN NATIONAL LABORATORY

Associated Universities, Inc.

Upton, New York 11973

AGS Division Technical Note

No. 184

IMPROVED MECHANICAJ, SEAJ FOR ALUMINUM VACUUM WINDOWS

E. Rodger

December 13,1982

Summary

This Technical Note analyzes past problems associated with the vacuum windows on our secondary emission chambers, describes a new seal, and its testing and performance to date.

Introduction

The proper operation of a secondary emission chamber generally requires vacuum levels of $10^{-9 / 10^{-8}}$ Torr. This in turn requires a bake-out at $300^{\circ} \mathrm{C}$. The high vacuum and bake requirement placed stringent sealing demands on the particle windows of the unit. In the past, these windows were made of 0.002 " thick stainless steel which was E.B. welded around its circumference. Once welded, they were generally leak tight. There were two problems, however; first, a high rate of rejects during the welding operation and second, the relatively high atomic number of stainless steel was in some cases objectionable. An aluminum window of 0.003" thick, 5052H35 was then tried making use of a mechanical seal as shown below.

\title{
PreVHOLS SRAL
}

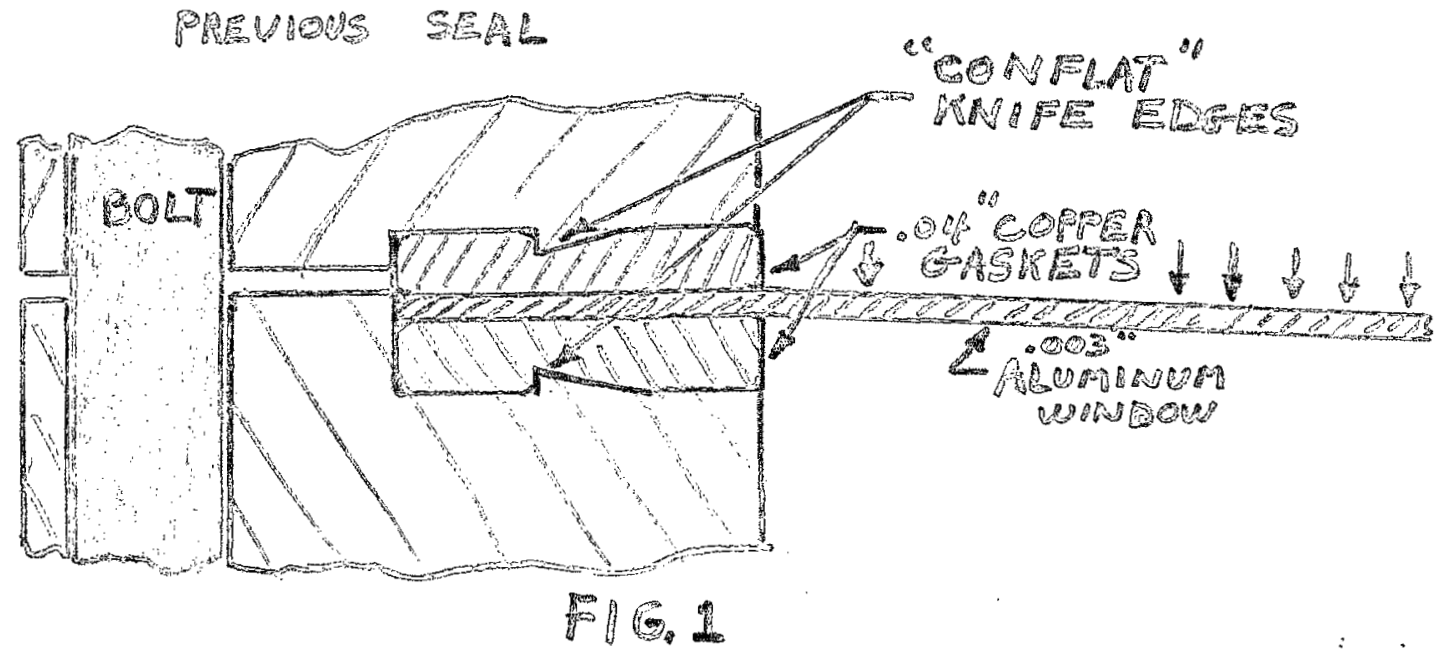


This design proved troublesome for two reasons. First, the copper-to-aluminum seal was marginal because the high stress of the knife edge-to-copper contact was dissipated in traveling through the copper. This was evident by the fact that the minute surface scratches on the copper gasket were not completely obliterated by the wind ow at the sealing area. Second, extensive copper-aluminum corrosion was observed across the seal area on a leaking unit. These observations lead to the design of a mechanical sea1 in which the stainless flange is clamped directly to the aluminum window as shown below.

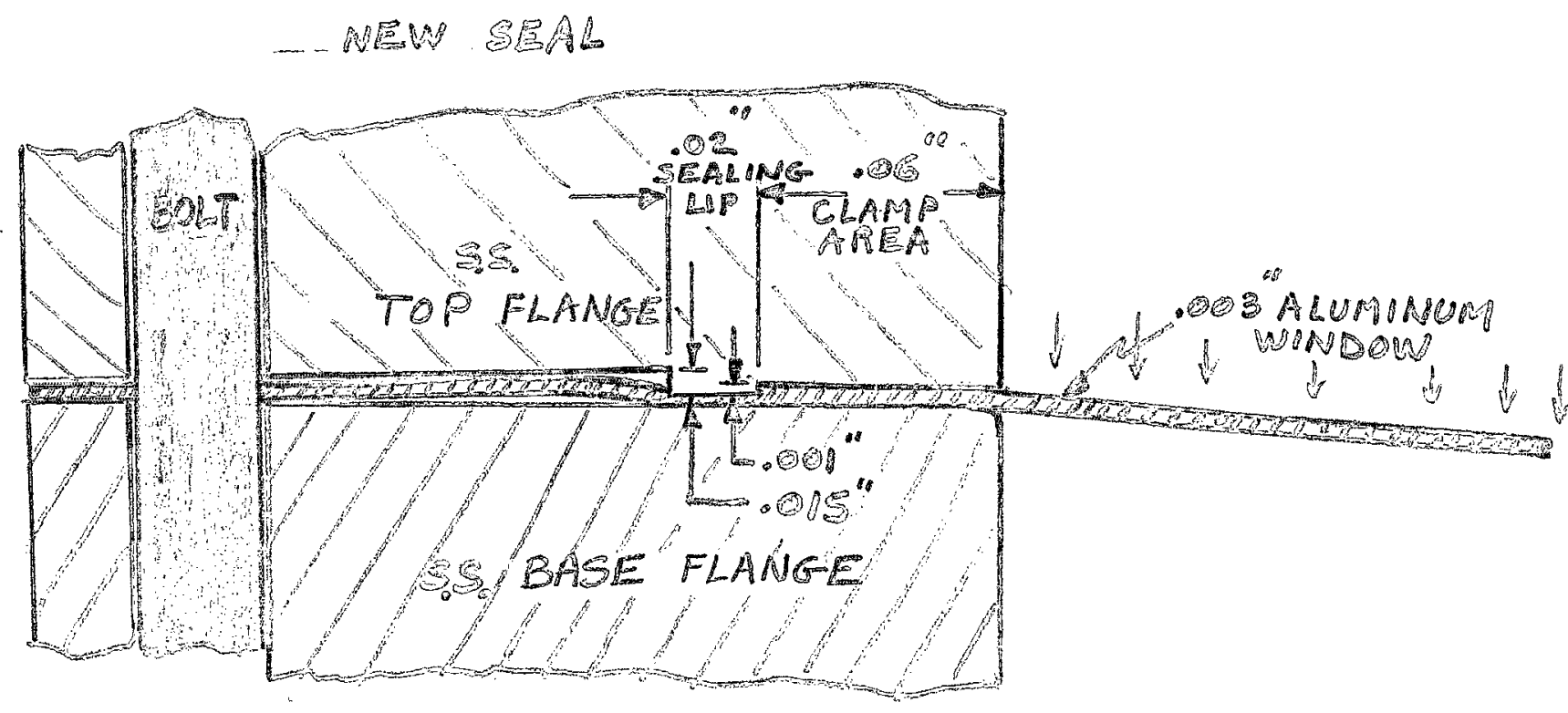

Fif. 2

This seal has three significant features:

1. Elasticity is built into the flange by the $0.015^{\prime \prime}$ relief in the bolt area. This causes the flange to take a slight cone shape under bolt tension. This maintains force on the sealing 1 ip over temperature extremes and differential expansions.

2. The sealing $1 \mathrm{ip}$ is raised $0.001^{\prime \prime} \pm 0.0005^{\prime \prime}$ above the clamping area and is 0.02 " wide. The contact area of the 1 ip with the aluminum is such that under 200 in-1bs. of bolt torque, the compressive yield of the aluminum wind ow is exceed by a factor of about three. The lip thus sinks into the a luminum until the clamp ing area comes in contact. 
3. The claming area is compressed against the wind ow with a stress which is approximately equal to the yield of the aluminum. This assures a good mechanical grip to resist the vacu um force.

Photographs taken at $38 x$ of the seal areas of the flange and wind ow are included. The machining marks on the stainless flange are readily observed embossed into the aluminum as well as the 0.001 " depression left by the sealing 1 ip (cross section photo). Also, note the microscopic grain and surface irregularities of the wind ow material are obliterated in the seal and $\mathrm{clamping}$ areas.

Testing to date consists of five seals made with the same flange set. None showed any leak on the most sensitive scale of a helium mass spectrometer as shown below.

\begin{tabular}{|c|c|c|}
\hline Test \# & Condition & Resu1ts \\
\hline 1 & As assembled (room temp.) & no leak \\
\hline 2 & Assembled then baked @ $250^{\circ} \mathrm{C}$ & $"$ \\
\hline 3 & $\begin{array}{l}\text { As sembled, baked } 2 \mathrm{hrs} \text {. at } \\
250^{\circ} \mathrm{C} \text {, cooled slowly to } 100^{\circ} \mathrm{C} \text {, } \\
\text { s prayed with cold water }\end{array}$ & $"$ \\
\hline 4 & $\begin{array}{l}\text { As sembled, baked } 2 \mathrm{hrs} \text {, at } \\
300^{\circ} \mathrm{C} \text {, cooled slowly to } 200^{\circ} \mathrm{C} \text {, } \\
\text { sprayed with cold water }\end{array}$ & " \\
\hline 5 & $\begin{array}{l}\text { As sembled, baked } 2 \mathrm{hrs.} \mathrm{at} \\
300^{\circ} \mathrm{C} \text {, sprayed with cold water }\end{array}$ & $"$ \\
\hline
\end{tabular}

An S.E.C. has been assembled using the new seal and is presently installed in the U Line for operational testing.

$\mathrm{mn}$

Distribution: Dept. Admin.

E. Jablonski

Y.Y. Lee

A. Soukas

J. Tuozzolo

W. Van Zwienen

P. Yamin 


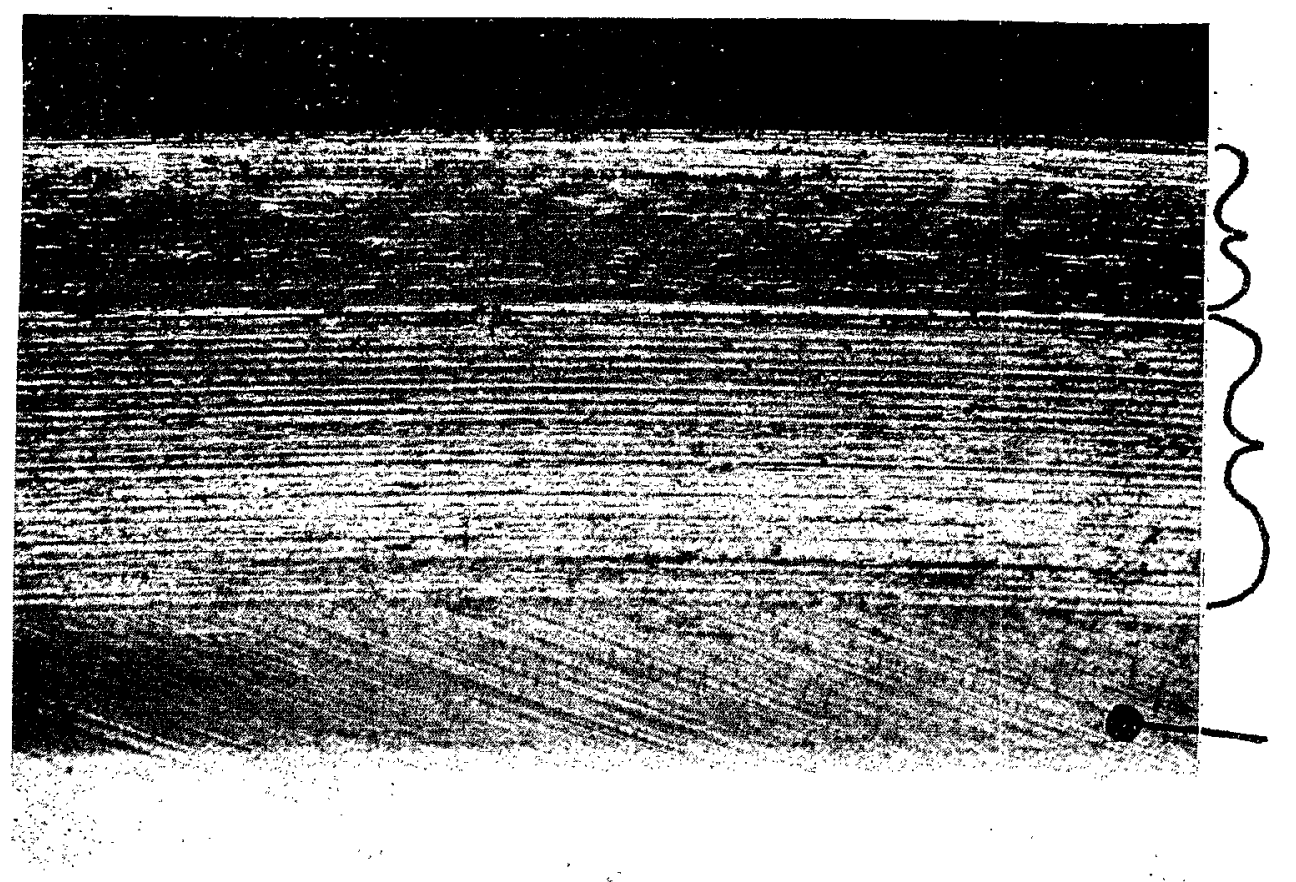

SEAL AREA

CLAMP AREA

FIG。 3

TOP FLANGE

(MATES WITH FIG. 3)

$(38 \mathrm{X})$

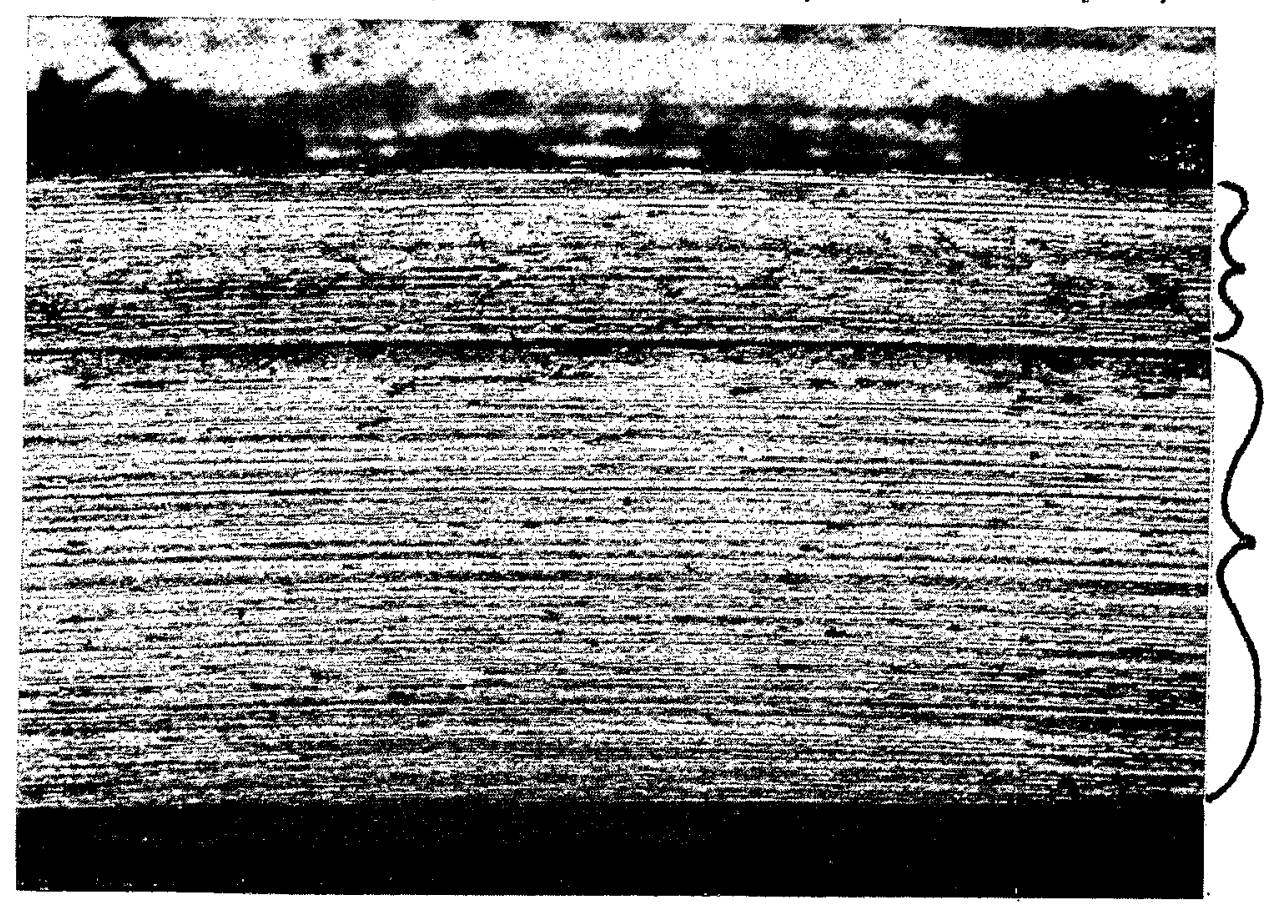

SEAL AREA

CLAMP AREA

FIG. 4 
WINDOW LOWER SIDE

$(38 . X)$

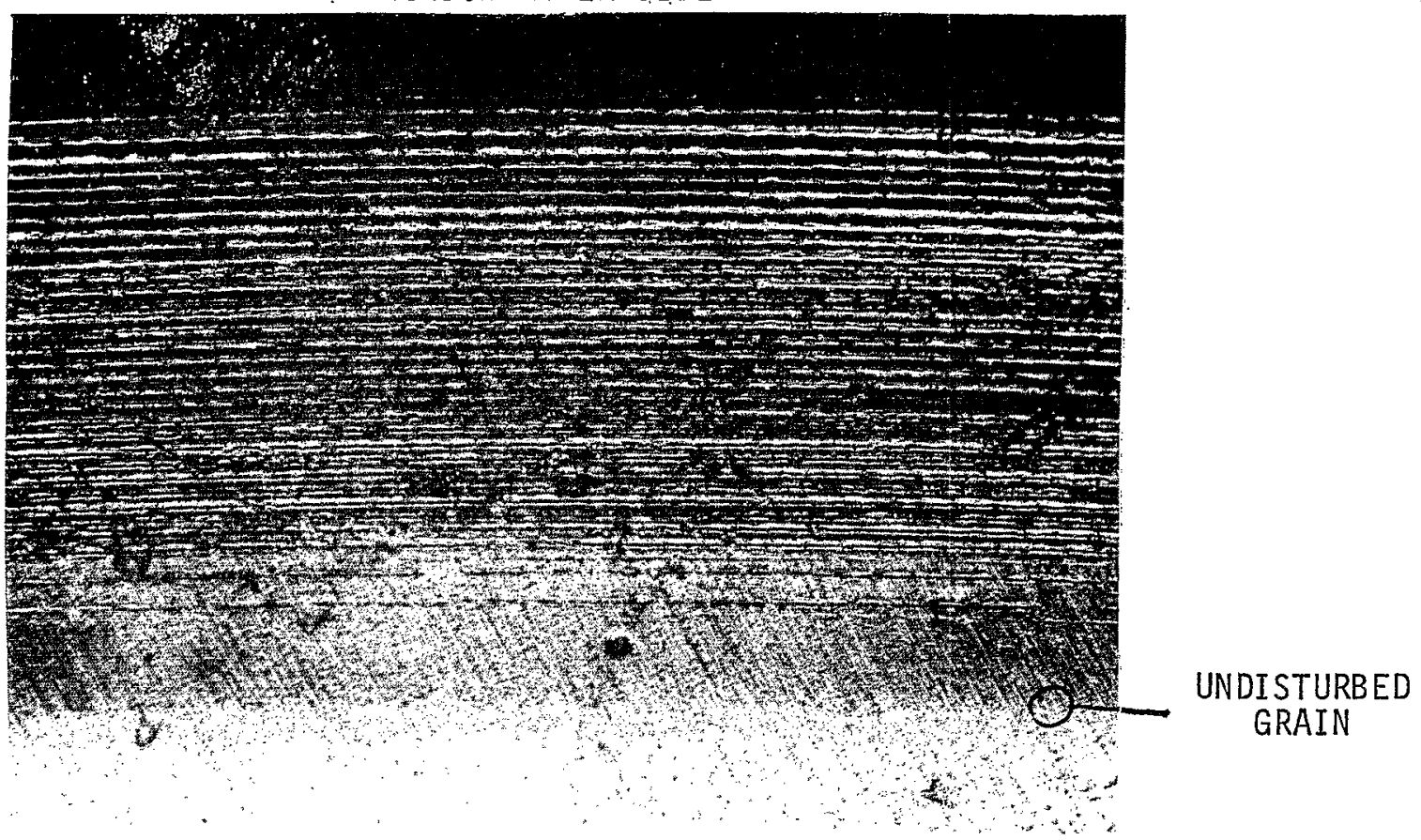

FIG. 5

BASE FLANGE

(MATES WITH FTG. 5)

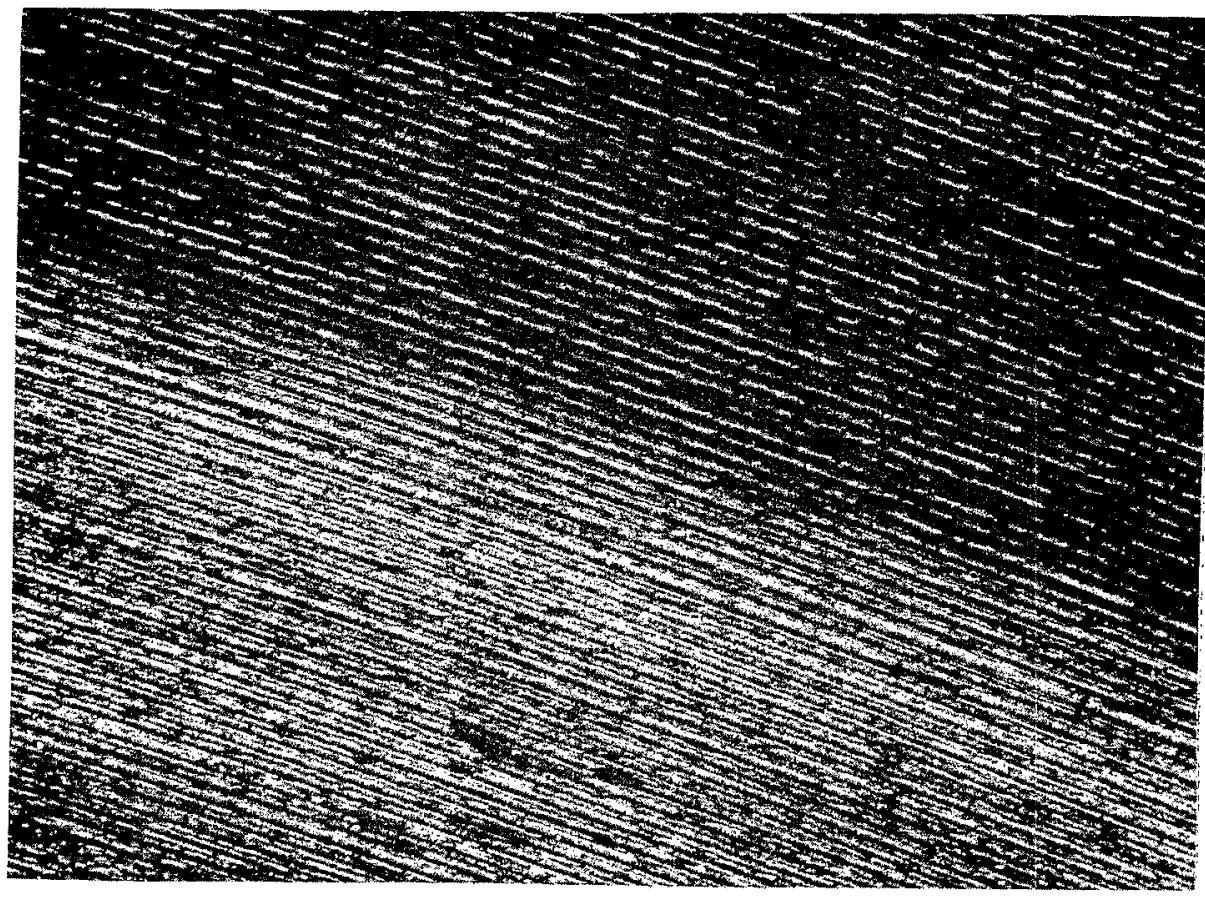

FIG. 6 
CROSS SECTION OF WINDOW

SEAL/CLAMP AREAS

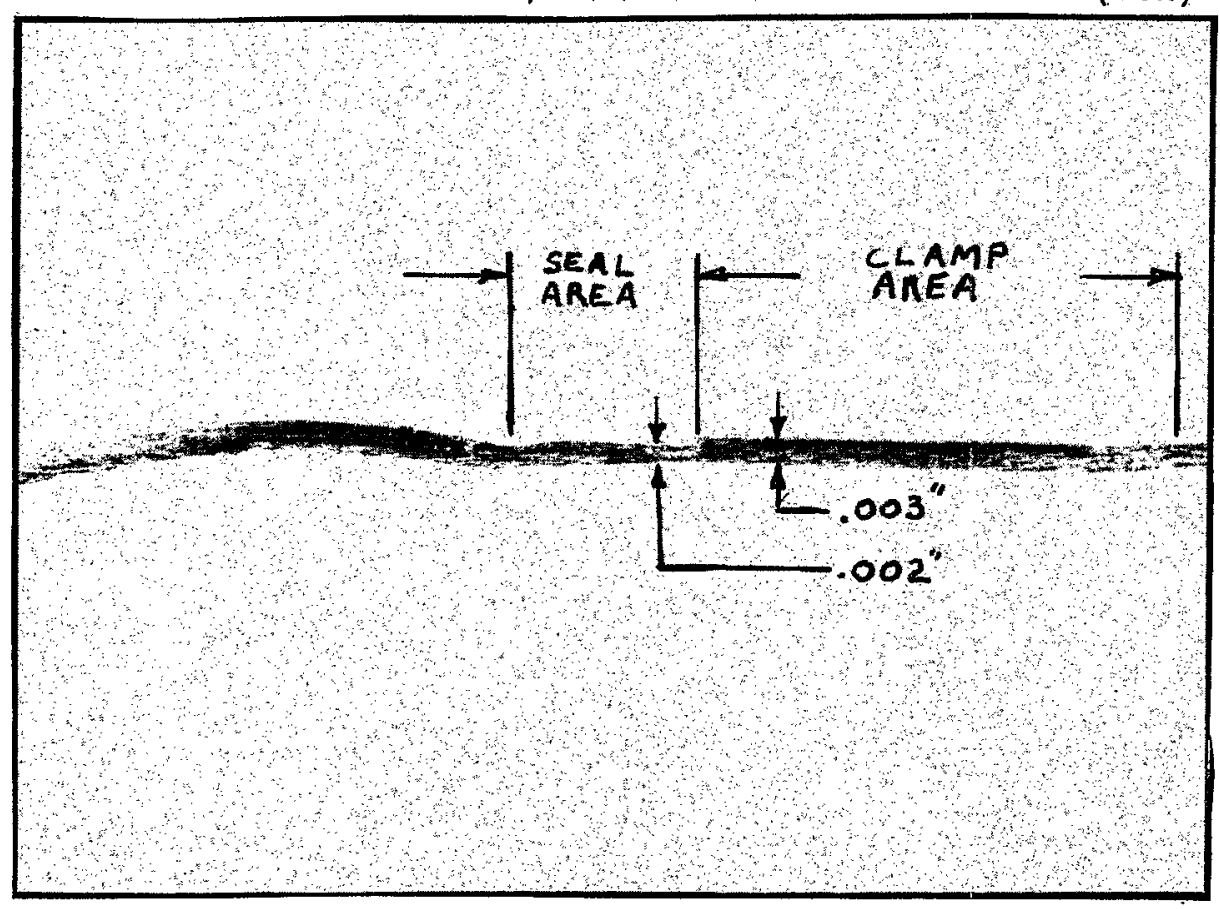

FIG. 7 